\title{
Solapamientos, lagunas e incoherencias en las políticas públicas para la población gitana del Estado español
}

Tina MAgAZZINI

\section{Introducción}

En las últimas décadas, la población gitana -la principal minoría étnica de España- ha recibido una gran atención tanto de la comunidad académica como de los políticos. En concreto, los estudios sobre la población gitana han vivido una evolución significativa tras los flujos migratorios de los Balcanes en los años noventa, y aún más tras la ampliación de la Unión Europea (UE) a los Estados de Europa Central y Oriental en 2004 y 2007 respectivamente. Todos parecen estar de acuerdo en que los gitanos se encuentran entre los colectivos más vulnerables y discriminados, y en que los niveles de desigualdad entre gitanos y no gitanos siguen creciendo.

Desde un punto de vista político y social, la preocupación "tanto por los efectos económicos de la desigualdad como por su capacidad disruptiva de la cohesión social" (este volumen, p. 5) se ha traducido en una mayor atención hacia la población gitana, con programas de inclusión y fondos europeos destinados específicamente a reducir la brecha existente. Desde un punto de vista académico, mientras un tiempo las características y condiciones de la población gitana eran consideradas un objeto de estudio casi exclusivamente antropológico, en la última década ha pasado a incluir disciplinas como la sociología, el derecho y las políticas públicas. Este proceso, si bien ha contribuido a una mayor interdisciplinariedad en abordar la cuestión, sigue por lo general fijándose en solo uno de los ejes de desigualdad a la vez: se trate de discriminación en ámbito de acceso a la educación, a la salud, a la vivienda, al mundo laboral; de infrarrepresentación a nivel político; de desigualdad por estatus migratorio; u de desprotección en tema de lengua e identidad cultural, los Roma experts se han vuelto altamente especializados en temas específicos, con pocas ocasiones (y a menudo herramientas) para intercambiar puntos de vista y hallazgos.

En suma, mientras está razonablemente bien estabelecido que una gran parte de la población gitana, en España como en el resto de Europa, siga sufriendo una discriminación múltiple, los estudios académicos y las medidas 
políticas ofrecen un enfoque que se centra sea en el aspecto de identidad cultural, sea en la desventaja económica, sin que se los dos marcos se crucen o dialoguen.

Es en este contexto que este capítulo busca cuestionar los presupuestos subyacentes que sustentan el concepto de "integración de los gitanos" en el Estado español, y de las políticas públicas que han resultado de dichos supuestos. De la misma manera que hay que distinguir entre derecho e implementación/interpretación del derecho para poner en evidencia la invisibilizacion de injusticias interseccionales, hay que distinguir entre políticas públicas y su aplicación/interpretación para ver si estas son efectivas en casos de desigualdades complejas.

Con el fin de desentrañar cómo las políticas de integración abordan -o no abordan- las múltiples desigualdades a las que se enfrenta el pueblo gitano, este capítulo ofrece, en primer lugar, una visión general de la historia del pueblo gitano en España; analiza posteriormente cómo se desarrollaron y evolucionaron las políticas dirigidas a la población gitana; y examina las categorías de inclusión y exclusión sobre las que se construyen.

En términos metodológicos, este capítulo se basa en un análisis del discurso de datos de primera mano (entrevistas con responsables de la formulación de políticas) y de documentos y literatura de políticas existentes. Como parte de un trabajo de doctorado más amplio, llevé a cabo 15 entrevistas semiestructuradas con responsables políticos y técnicos responsables de desarrollar o implementar políticas de inclusión para la población gitana. Debido a que el trabajo de campo se llevó a cabo entre 2013 y 2015, es posible que no se tengan en cuenta algunas iniciativas o medidas recientes. Sin embargo, el panorama general que surge de informes recientes sobre la situación de la población gitana en España (Carrasco \& Poblet, 2019) muestra que el panorama no ha cambiado significativamente en los últimos años y que el marco de las políticas de inclusión/integración para población gitana sigue siendo el mismo.

\section{La "inclusión excluyente" en España: una breve historia}

Las primeras huellas de la presencia gitana en España se remontan al siglo XIV, documentadas por una carta de seguro otorgada en 1425 por Alfonso $\mathrm{V}$ a grupos de personas que fueron llamadas o se autodenominaban egipcianos (Martín 2017, p. 16). Durante las primeras décadas de su presencia en la península, los gitanos fueron generalmente asociados a los peregrinos y, por tanto, no fueron retratados de forma negativa. Sin embargo, España no 
tardó en ponerse al día con las leyes vigentes en otros países europeos, ${ }^{1}$ y en 1499 aprobó una Real Pragmática según la cual "los egipcianos que andan vagando por nuestros reinos y señoríos" disponían de un plazo de dos meses para instalarse y tomar un "oficio conocido", trabajo estable, bajo pena de expulsión o de muerte en caso de incumplimiento (Vega Cortés 1997). Esta pena se convirtió en seis años de prisión en 1539, pero en los tres siglos siguientes, se publicaron otros más de 280 Decretos contra los gitanos, lo que ha llevado a Leo Charnon-Deutsch a hablar de una "obsesión" española (Charnon-Deutsch 2004). ${ }^{2}$

El 30 de julio de 1749 es una fecha significativa que marca el acontecimiento, considerado el más dramático, sufrido por el pueblo gitano en España: la llamada 'Gran Redada'. Esto significó la persecución y el encarcelamiento general de todos los gitanos, con el objetivo explícito de internarlos en campos de trabajo y exterminarlos; circunstancia que no se revirtió definitivamente hasta 1763 (Gómez Alfaro 1993).

En 1783, un Decreto de Carlos III otorgó a los gitanos la ciudadanía española, eliminando los requisitos de tener un "oficio conocido". Tales "privilegios" o "carta de ciudadanía" dependían, sin embargo, de la asimilación; es decir, de tres condiciones: el abandono de la vestimenta tradicional, del estilo de vida nómada (aunque se estima que, en 1783, cerca del $90 \%$ de la población gitana en España ya era sedentaria) y de la no utilización de la lengua caló en público. En el mismo Decreto se declaraba que el término "Gitano" sería sustituido por "Castellano Nuevo", ya que "debe dejarse de decir gitano, ya que todos los ciudadanos son iguales". También cabe destacar que la ley, que siguió vigente hasta 1878, mencionaba expresamente la "integración de los gitanos" como objetivo deseado, y la posibilidad de imponer "penas a los que obstaculicen la integración de los gitanos" (Vega Cortés 1997).

Charnon-Deutsch sostiene que la representación cultural de los gitanos en España y los estereotipos en torno a la "gitanidad" proporcionan una base útil para el estudio de la evolución del nacionalismo español. Su principal argumento es que la relación entre las identidades gitana y española debe analizarse a través de las fuerzas económicas y productivas que inciden en las prácticas discursivas que a su vez participan en la construcción de la

\footnotetext{
${ }^{1}$ Entre 1450 y 1500 muchos gitanos fueron expulsados, bajo pena de muerte, de Francia, Suiza, Alemania, y en 1540 también de Gran Bretaña y Bélgica.

${ }^{2}$ Las persecuciones de los gitanos que se iniciaron en el siglo XVI no son, sin embargo, un caso único, y se sitúan históricamente entre las persecuciones españolas que también se dirigieron contra los judíos (con el edicto de expulsión de 1492) y el período final de la Reconquista, seguidas por los edictos que proscribieron el islam, la conversión forzada de los musulmanes y los Decretos sobre la expulsión de los moriscos.
} 
identidad nacional, con especial atención a la fusión de la identidad gitana y de la identidad andaluza, que "en el siglo XX llegó a ser sinónimo de español tanto fuera como, en cierta medida, dentro del ámbito cultural español" (Charnon-Deutsch 2004, p.22).

En efecto, la cultura española tiene una doble relación con la narrativa del orientalismo, que es parte integrante de la civilización europea y que "expresa y representa esa parte cultural e incluso ideológica como modo de discurso con instituciones de apoyo, vocabulario, erudición, imágenes, doctrinas, incluso burocracias coloniales y estilos coloniales" (Said 1978). Como componente constitutiva de su identidad histórica, esta "alteridad" se ha proyectado hacia un gitano imaginario narrado en versos y obras de escritores españoles, desde Cervantes hasta García Lorca. Pero también ha habido, a partir del siglo XVIII, y sobre todo después de 1881 -año en el que la palabra "flamenco" aparece simbólicamente nombrando una especie de espectáculo en un café cantante- una proliferación de imágenes sobre gitanos.

Ángel Vargas, un estudioso andaluz, basándose en el historiador Paul Hauben, ofreció una interesante y provocativa explicación de la aparente idiosincrasia española hacia los gitanos en la segunda mitad del siglo XVII: la de pasar en muy poco tiempo del encarcelamiento masivo de los gitanos por su identidad, a la popularización de la imagen de los gitanos en la literatura y como personajes en el escenario de los mayores teatros de Cádiz, Sevilla y Madrid (Hauben 1979). Lo que Ángel Vargas sugiere es que el intento de exterminio de los gitanos en España fue, en gran medida, producto de uno de los principios básicos de la Ilustración, percibido como problemático por la aristocracia: la idea de "igualar" a todos los ciudadanos y eliminar las minorías. El objetivo de la "Gran Redada" fracasó porque los gitanos recibieron el apoyo y la solidaridad de algunos alcaldes y sacerdotes católicos (a pesar de que la Iglesia había aprobado oficialmente la Redada), pero también -y de forma importante- de sectores de la nobleza y de la nueva clase media. Los gitanos se convirtieron, en definitiva, en el símbolo del antiguo régimen, por lo que cierta parte de la población realizó tales actos no tanto para apoyar a la minoría gitana, sino más bien como una declaración política contra la Ilustración y en defensa del antiguo régimen.

Con la Constitución de 1812, ${ }^{3}$ la ciudadanía española para los gitanos se hizo automática al comprobar que habían nacido en España. Ya no estaba ligada, por tanto, a los requisitos para asimilarse y ser "productivos". Sin embargo, en el siglo XX, bajo la dictadura franquista, la situación volvió a empeorar para la comunidad gitana, con la prohibición de hablar en Caló y

\footnotetext{
${ }^{3}$ Según el Decreto de 1783, a los gitanos desempleados o "improductivos" se les quitarían sus hijos.
} 
con la regulación de la Guardia Civil del 14 de mayo de 1943, vigente hasta 1978, y que se refería específicamente a la "necesidad de vigilar y controlar a los gitanos" (Congreso de los Diputados 1978).

Al mismo tiempo, la ideología nacional católica contribuyó a enmarcar la presencia de los gitanos españoles como objeto de caridad, a la vez que ampliaba y desplazaba las categorías de los que se consideraban "asociales" hacia otros grupos: ${ }^{4}$

La época franquista se caracteriza por una dicotomía en la que, por un lado, hay una represión cultural total e intolerante contra las minorías en general y contra el pueblo gitano en particular, pero, por otro lado, las clases dominantes, imbuidas del concepto católico de 'caridad', inician acciones tibias y descoordinadas hacia la comunidad gitana para integrarla en la cosmovisión religiosa, cultural y social de los payos. Los programas financiados por la Administración Central y diseñados por organizaciones católicas, trataron de 'promoverlos', 'integrarlos' o 'enseñarles' a ser payos. A la ideología fundamentalista dominante, tan convencida de su superioridad, le resultaba muy difícil abandonar una perspectiva asimilacionista (Mathioudaki 2010, 10).

Con la Constitución de 1978, todos los ciudadanos españoles fueron declarados iguales ante la ley (art. 14) y se estableció que es "responsabilidad de los poderes públicos promover condiciones que garanticen que la libertad y la igualdad de las personas y de los grupos a los que pertenecen sean reales y efectivas, eliminar los obstáculos que impiden o dificultan su pleno disfrute y facilitar la participación de todos los ciudadanos en la vida política, económica, cultural y social" (art. 9.2).

En 1979, se creó una Comisión Interministerial Gitana con el objetivo de estudiar los problemas que afectan a la comunidad gitana, así como la coordinación y administración relacionadas con el desarrollo del pueblo gitano, el respeto de su cultura y su plena integración y convivencia en la sociedad, pero no fue eficaz y, en última instancia, no se tradujo en mucho más que una declaración de intenciones. En 1982 se constituyó como entidad jurídica la asociación Secretariado General Gitano, ${ }^{5}$ una ONG católica progitana que había estado funcionando desde mediados de los años sesenta, y en el mismo año el Instituto de Sociología Aplicada de Madrid publicó el Libro Blanco sobre los gitanos. En 1983 el Decreto 1174/1983 estableció

\footnotetext{
${ }^{4}$ La ley de 1933 de vagabundos (Ley de Vagos y Maleantes) fue modificada en 1954 para incluir a la homosexualidad entre las conductas consideradas "asociales", y nuevamente en 1970 en la ley sobre peligrosidad y rehabilitación social, incluyendo a la prostitución, el tráfico de drogas, la pornografía y la inmigración ilegal (Presidencia del Consejo de Ministros 1933; BOE 187 1970).

${ }^{5}$ En 2001, el nombre de la asociación cambió a Fundación Secretariado General Gitano, y en 2004 a Fundación Secretariado Gitano (FSG).
} 
medidas de educación compensatoria para "las personas que se encuentran en situación de desigualdad en el acceso a la educación y en su rendimiento debido a su situación económica, condición social o residencia", que formalizaron y estructuraron las denominadas "escuelas puente" ya existentes, creadas en los años setenta mediante un acuerdo entre el Ministerio de Educación y el Secretariado Gitano.

En 1985, el Congreso de los Diputados aprobó una moción inicial para la creación de un Plan Nacional de Desarrollo Gitano, financiado por el presupuesto general del Estado y que se puso en marcha en 1989 (Congreso de los Diputados, 1985). Mientras tanto, la Comunidad Autónoma de Andalucía creó la Secretaría para la Comunidad Gitana (1985) y la Federación de Asociaciones Gitanas de Andalucía (1988), y el País Vasco, Cataluña y algunas otras Comunidades Autónomas también empezaron a desarrollar sus propios Planes de Inclusión del Pueblo Gitano. El Plan Nacional de Desarrollo Gitano, establecido en 1985, así como los planes regionales, tenían el objetivo general de promover la igualdad de oportunidades de los gitanos en relación con el resto de la población en el acceso a los servicios públicos de educación, salud, vivienda, empleo, etc.

En este sentido, si bien implícitamente, ya se reconocía la interseccionalidad de la desventaja socioeconómica -no tener un título escolar afecta a la posibilidad de conseguir un buen trabajo, lo cual tiene consecuencias en vivienda y salud-, pero el tema clave sigue siendo las desventajas socio-economicas, sin abordar las consecuencias culturales y identitarias de siglos de asimilacionismo.

En 1986 se fundó la Unión Romaní española y Juan de Dios Ramírez Heredia, el primer político gitano español, fue elegido diputado al Parlamento Europeo por el Partido Socialista Obrero. Desde finales de los años ochenta y principios de los noventa, el número de asociaciones gitanas y su voz han aumentado considerablemente, y en 1999 la Comisión de Políticas Sociales y Laborales del Congreso de los Diputados creó un subcomité sobre inclusión de la población gitana. En cuanto a las políticas de Estado, según un responsable español de las políticas de inclusión gitana:

Había prácticamente un consenso, aunque no explícito, de que la integración de los gitanos en España debía llevarse a cabo simultáneamente mediante un enfoque de integración -es decir, incluir a los gitanos dentro de las medidas generales de bienestar social- y, a continuación, proporcionar medidas específicas para compensar las desventajas. Por supuesto, esto se desarrolló mucho más a partir del año 2000, cuando los Fondos Sociales Europeos pusieron a disposición fondos a través del Programa Operativo 
de Lucha contra la Discriminación 2000-2006, y más tarde con la Estrategia ${ }^{6}$ para la Población Gitana, que consolidó este modelo de funcionamiento (entrevista, abril 2015, Madrid).

Especialmente a partir de los 2000, se han puesto en marcha varios planes regionales para el desarrollo o la promoción de la población gitana, y se han revisado varios programas estatales destinados a la inclusión social en general, al fin de incluir políticas o ámbitos específicos dirigidos a población gitana. Un ejemplo es el Programa Operativo de Lucha contra la Discriminación (ADOP) 2000-2006, en el que se incluyeron objetivos e indicadores específicos para la población gitana. Esta tendencia (que en cierto sentido podría ser calificada como interseccional) continuó en el ADOP 2007-2013, y el Plan Nacional de Inclusión 2008-2010 incluyó medidas específicas para la población gitana, como la adopción de un plan de acción específico a nivel estatal y planes autónomos, así como el desarrollo de las funciones del Consejo Estatal del Pueblo Gitano.

No todas las políticas adoptaron un enfoque desarrollista, y han surgido iniciativas, aunque más tarde comparadas con las socioeconómicas, en relación con la cultura y la identidad gitana. Los dos más notables son el Consejo Estatal del Pueblo Gitano y el Instituto de Cultura Gitana. En 2005, el Congreso de los Diputados aprobó una moción inicial por la que se creó el Consejo Estatal del Pueblo Gitano (regido por el Decreto 891/2005) para promover la cultura, la historia, la identidad y la lengua Caló, y para servir de órgano colegiado interministerial de consulta y asesoramiento destinado a la colaboración entre el movimiento asociativo gitano y la Administración General del Estado (Ministerio de Trabajo y Asuntos Sociales, 2005), y ese mismo año España se unió a la Década para la Inclusión Gitana. En 2007 se creó el Instituto de Cultura Gitana, con el apoyo del Ministerio de Educación, Cultura y Deporte, y en 2010 el Gobierno español aprobó el Plan de Acción Gitana 2010-2012 (Resolución del Consejo de Ministros de 9 de abril de 2010).

Con justificación en estas medidas, a pesar de un pasado de persecución y marginación del pueblo gitano, a nivel tanto europeo como internacional hoy en día España se toma a menudo como un ejemplo positivo de integración (Ovalle y Mirga 2014; Bereményi y Mirga 2012; Magazzini 2018). En 2010, por ejemplo, la revista Time publicó un articulo titulado «La Tolerancia de España con los gitanos: ¿Un modelo para Europa?» (Cala 2010) en el cual se describía la "excepción española" comparándola con otros países. Asimismo, un artículo del New York Times con el titular «En España, los

\footnotetext{
${ }^{6}$ En el documento se menciona la creación, en 2007, del Instituto de Cultura Romaní, y se incluye la creación de material educativo sobre la cultura y la historia gitana para que sea incorporada en el curriculum escolar.
} 
gitanos tienen un camino más fácil hacia la integración» (Daley y Minder 2010) reforzó el mensaje que las políticas españolas para los gitanos hayan sido un éxito, aunque algunos estudios hayan cuestionado esta versión (Vallvé 2009; Bereményi y Carrasco 2015; Carrasco y Poblet 2019).

Pero ¿qué comunidades y cuales personas gitanas se han beneficiado de las políticas de integración? Si se puede hablar de cierta "interseccionalidad" en políticas de inclusión que están dirigidas específicamente a los gitanos que se encuentran en una situación de desventaja socioeconómica, ¿hasta dónde llegan esas políticas?

Un tema es que por lo general, las políticas españolas no distinguen entre población gitana nacional y población gitana no nacional, a pesar del hecho que afectan a distintos grupos gitanos de manera diferente ya que los gitanos no españoles y las mujeres gitanas migrantes en particular a menudo se ven afectados negativamente por estas políticas, únicamente atenta a la situación económica y migratoria pero, en muchos casos ciegas a la discriminación múltiple que padecen (Magazzini y Piemontese 2016, Vrabiescu 2019).

\section{Integración de los gitanos en las políticas públicas}

En este contexto, ¿cómo podemos y debemos situar el concepto de "integración de los gitanos"? El "reconocimiento" o la "construcción" de la población gitana como categoría vulnerable -un grupo considerado especialmente susceptible a la exclusión social (Comisión Europea 2010)-, y la representación de la exclusión de los gitanos como un problema de tipo público tiende a diferir de las cuentas de otros grupos desfavorecidos o marginados. Aunque la Comisión Europea no ha señalado (ni siquiera mencionado) la exclusión de los gitanos en la mayoría de sus documentos sobre bienestar, crecimiento económico e inclusión social ha desarrollado un conjunto paralelo y creciente de informes, directivas y recomendaciones que abordan a los gitanos como un grupo especialmente desfavorecido. De la misma manera, otras organizaciones internacionales, investigadores y a menudo también activistas gitanos han tendido a reforzar la idea de que los gitanos se enfrentan a un tipo de obstáculos que son completamente diferentes de los problemas de otros grupos o de la población mayoritaria y que los sitúan en una categoría aparte. Así pues, el creciente debate en torno a la exclusión de los gitanos a nivel europeo ( $\mathrm{y}$ la necesidad de su "integración"), junto con el creciente aislamiento del debate sobre la exclusión social que afecta a otros grupos marginados, ha dado lugar a la hibridación de un discurso muy étnico pero que, al mismo tiempo se centra en la pobreza y la exclusión. 
La indeterminación de la noción de integración está estrechamente relacionada con lo que se considera que son los objetivos de la integración: si el "problema" subyacente que la integración debe abordar se considera en términos de distancia cultural de la mayoría o como desventaja socioeconómica, y si se entiende que la minoría debe integrarse en la mayoría o si la sociedad en su conjunto debe someterse a un proceso de integración como respuesta a una mayor diversidad.

Para entender la posición de España en este debate, a continuación, vamos a analizar las medidas de integración de los gitanos que existen en el Estado español, con especial atención a la Estrategia Nacional de Integración de los Gitanos (NRIS), que representa la piedra angular de la política de integración de los gitanos en términos de fijación de metas y objetivos específicos a alcanzar. Como mencionado en la introducción, el análisis del NRIS español es acompañado por entrevistas realizadas a los responsables de la formulación de políticas y a los administradores que han participado en la formulación, en el diseño y en la aplicación de políticas públicas dirigidas a la población gitana. Las narrativas políticas sobre lo que significa la integración de los gitanos, o sobre lo que debería ser, y sobre lo que quisieron decir con ello a la hora de elaborar las políticas, visibilizan de alguna manera cuáles son los objetivos y las expectativas de dichas medidas, y establecen una jerarquía sobre sobre el tipo de desigualdad(es) que hay que abordar en primer lugar (y si esas son "compatibles" la una con la otra).

En 2012, España presentó a la Comisión Europea una Estrategia Nacional de Integración de la Población Gitana. Mientras que, al no existir una definición oficialmente acordada de "integración", los países tenían libertad para interpretar y utilizar el término, la Comunicación de 2011 "Un marco de la UE para las estrategias nacionales de integración de la población gitana hasta 2020" identificaba la tarea de la siguiente manera:

... dado que una mera falta de discriminación no basta para combatir la exclusión social de los gitanos, la Comisión pide a las instituciones de la EU que apoyen el presente Marco Europeo de Estrategias Nacionales de Integración de los Gitanos. Es un medio de completar y reforzar la legislación y las políticas de igualdad de la UE ocupándose, a nivel nacional, regional y local, y también dialogando con ellos e implicándolos en el proceso, de las necesidades específicas de los gitanos en relación a un acceso equitativo al empleo, la educación, la vivienda y la sanidad (Comisión Europea 2011, 173 final, p. 3).

En el período 2011-2012, España ya contaba con una trayectoria bastante larga de planes y prácticas de inclusión de los gitanos para la elaboración de su Estrategia Nacional de Integración de los Gitanos. De hecho, el Marco Europeo para la Integración de los Gitanos presentado por la Comisión Europea tomó prestadas algunas características -como el 
enfoque en cuatro áreas prioritarias (educación, salud, vivienda y empleo)- de la estructura y los objetivos establecidos por la Década para la Inclusión Gitana (de la que España fue una fuerte impulsora) y del enfoque español "explícito, pero no exclusivo". Por lo tanto, no sorprende que el Marco de la UE 2011 haya sido bien acogido por el gobierno español y que España no haya encontrado grandes dificultades a la hora de elaborar una Estrategia Nacional que se ajustara a las directrices europeas. Sin embargo, cabe destacar la forma en que se utiliza el término "integración", ya que no era el término elegido por España: la Spanish National Roma Integration Strategy 2012-2020 se titula en su versión española Estrategia Nacional para la Inclusión Social de la Población Gitana en España 2012-2020, en la que se opta por utilizar el término "inclusión social" en lugar de "integración" (Ministerio de Sanidad Servicios Sociales e Igualdad de España, 2012). Aún más relevante que la preferencia del gobierno español por el término "inclusión" sobre "integración" es que la palabra "integración", cuando se emplea, se utiliza como sinónimo de facto para superar la marginación socioeconómica. En el documento se describen los desafíos que la Estrategia pretende abordar:

La población gitana en España, en términos generales, ha experimentado importantes avances sociales en los últimos 40 años; tales avances han venido de la mano de la democratización de la sociedad española, el crecimiento económico del país, la construcción de un Estado social, el acceso generalizado a los sistemas de bienestar social (especialmente vivienda, educación, salud, y servicios y prestaciones sociales) y las medidas y programas específicos dirigidos a compensar las desventajas. No obstante, todavía queda un camino largo por recorrer para alcanzar la equidad en las cuatro áreas fundamentales para la inclusión social y en las que se centrarán los objetivos de esta Estrategia Nacional para la Inclusión Social de la Población Gitana en España (Gobierno de España 2012, p. 5).

Una sección titulada «La Estrategia Nacional de Integración de los Gitanos 2020: Definición y objetivos» ofrece una descripción detallada de los objetivos destinados a mejorar las condiciones de vida de la población gitana, e incluye objetivos cuantificables a medio plazo que deben alcanzarse para 2015 y 2020 en cada uno de los ámbitos clave de la inclusión social: educación, salud, empleo y vivienda. Sin embargo, no ofrece una definición explícita de lo que se entiende por "integración" ni por "inclusión". La siguiente cita de una persona que contribuyó al marco conceptual de la Estrategia española ayuda a entender cómo y por qué se adoptó la "integración” en la Estrategia para empezar:

La semántica siempre tiene matices y es muy importante. Y no es lo mismo decir 'subnormal' que decir 'discapacitado', o que decir 'persona con discapacidad'. La terminología también ha ido evolucionando y avanzando [...] pero básicamente en la Estrategia nacional se utiliza el término que establece el marco europeo; simplemente se ha utilizado este término por 
eso. Pero cuando luego se define lo que se entiende, sí que se definen los principios para la integración de los Gitanos y básicamente lo que se entiende por integración es la mejora de las condiciones de vida de la población gitana, su normalización en la sociedad respectando sus diferencias y sus particularidades. Y por esto la Estrategia española no solamente se reduce a los cuatro ejes que establece el marco europeo (educación, vivienda, etc.) sino que también incluyó a aspectos relacionados con cultura, la discriminación etc.; aspectos que siempre se han trabajado y que se consideran importantes (entrevista, abril 2015, Madrid).

Otros actores encargados de la formulación de políticas o de su aplicación ofrecieron una interpretación parecida del concepto de integración, coherentes con la idea de que se trata de una cuestión de "mejorar las condiciones socioeconómicas de los gitanos", y a menudo se hace referencia a este reto en términos de "normalizar" o "nivelar" la tasa de desempleo, los alcances en cuanto a educación, etc. de las personas gitanas.

Si bien el Ministerio de Salud, Servicios Sociales e Igualdad (que fue el encargado de elaborar la Estrategia y sigue siendo el Punto Nacional de Contacto para su gestión e implementación) parece haber incorporado en el documento algunos elementos culturales avanzados por el Secretariado Gitano, la Unión Romaní, la Fundación Instituto de Cultura Gitana y otras entidades, el enfoque y el benchmarking permanecieron fuertemente centrados en las dimensiones económicas, y en particular en las dimensiones de empleo y escolaridad. Un político español describió el 'modelo español' de integración de los gitanos y su línea de acción en los siguientes términos:

La clave del modelo español ha sido un enfoque programático que ha priorizado las medidas para corregir las desigualdades y mejorar las condiciones de vida por encima de otros enfoques más centrados en cuestiones de identidad, defensa de las minorías o participación política, que de hecho también han empezado a surgir, pero más tarde. Es decir, privilegiamos el enfoque socioeconómico por encima del étnico (entrevista, octubre 2014, Barcelona).

Esto no significa que exista unanimidad entre los varios actores sobre el éxito de este enfoque, ni que su aplicación haya sido coherente o uniforme en las diferentes comunidades autónomas (Bereményi y Mirga 2012). Pero, sin embargo, tanto los planos de integración como las entrevistas con técnicos muestran un acuerdo general en entender el concepto de integración como "elevar el nivel de vida de la población gitana", en cuanto españoles. El concepto de identidad y cultura gitana no se desestima ni se excluye totalmente en la Estrategia Nacional de Inclusión, pero tampoco son los principales ejes de lo que requiere o implica "integrar" a la población gitana. Entre un enfoque identitario y uno socioeconómico, la toma de posición del gobierno español puede resumirse en la siguiente cita: 
Digamos que durante años ha habido en todos los movimientos, en España y también en Europa, digamos un mal empoderamiento o un empeoramiento mal entendido de los gitanos con un enfoque en algunos casos muy centrado en los argumentos étnicos de la integración de los gitanos. Pues yo no comparto esta visión, de que sea el enfoque adecuado. Soy más partidario de un enfoque intercultural, por muchas razones, lo cual no quiere decir que esté en contra: todo lo contrario, estoy completamente a favor del empoderamiento de los gitanos, o sea creo que hay que buscar el protagonismo de los gitanos. Pero cuando uno tiene un enfoque étnico, y esto lo he visto bastante en los países del Centro Europa, el riesgo fundamental es que la cuestión gitana se convierta en un problema de los gitanos, y no en un problema de la sociedad, y por lo tanto se crean organismos especializados y por supuesto se les delega a estos organismos la integración de los gitanos. Y eso no funciona, y en ningún caso se ha demostrado que esto funcione, porque al final la clave de la integración de los gitanos está fundamentalmente en el acceso a los servicios normalizados, en las políticas del Ministerio, que luego tienen que ser compensadas con medidas especificas (entrevista, abril 2015, Madrid)

\section{Categorías de igualdad: ¿qué discriminación, qué integración?}

Aunque exista cierta unanimidad en la identificación de la "igualdad" como el objetivo último de las políticas de integración de los gitanos, vale la pena intentar desentrañar qué concepto de igualdad sustenta el intento de España de promoverla. Al corregir las desigualdades, se supone que los gitanos se convierten en "iguales". Pero ¿igual en qué, y a quién?

Los criterios que emergieron de los documentos y las entrevistas se pueden agrupar en cuatro ejes principales: la dimensión nacional, cultural, territorial y económica (Magazzini 2018).

La categoría más aparente y fácilmente identificable es la de la ciudadanía legal. En España, la gran mayoría de personas gitanas son ciudadanos españoles, identificados y presentados como una "vieja minoría" en los documentos de integración e inclusión. En los casos en que los programas de integración incluyan a gitanos no españoles, esto se hace explícito especificando que los "gitanos rumanos" o gitanos inmigrantes también pueden beneficiarse de las "políticas de integración para gitanos".

La consecuencia de este enfoque es doble: por un lado, ha habido una elección consciente y un esfuerzo por parte de los responsables políticos para no identificar a los gitanos a través de políticas dirigidas a ellos de forma exclusiva en cuanto grupo étnico. Las políticas de integración españolas tienden a garantizarse que el acceso a determinados servicios esté disponible a nivel general para todas las personas que se encuentren en situación de desventaja socioeconómica. Esto, unido al respaldo y al apoyo oficial a la creación de institutos como el Secretariado Gitano y el Instituto de Cultura 
Gitana, ha conseguido promover una representación de la población gitana en España como una minoría que, a pesar de vivir en situación de marginalización, pertenece a la sociedad española y constituye una parte integral de la misma (aunque a menudo el imaginario promovido se limite a la imagen estereotipada de los flamencos y de los vendedores ambulantes).

Por otro lado, al centrarse en la cuestión de la ciudadanía para quitarle importancia al aspecto étnico, este enfoque ha hecho invisible y ha dejado fuera de la "comunidad imaginada" (Anderson 1991) a los gitanos no españoles. Como se puede destacar en una evaluación de la Estrategia española:

Es muy importante entender la diferencia entre los gitanos españoles, que están bien integrados aunque, de vez en cuando, se enfrenten a la discriminación en los derechos sociales y económicos y a un racismo creciente del resto de la sociedad, y los gitanos que han llegado recientemente a España, viven en condiciones económicas difíciles y se enfrentan a discriminaciones raciales considerables en todos los ámbitos de la vida (European Roma and Travellers Forum 2016, p. 3).

Un ejemplo claro es el barrio de chabolas de Gallinero, a un kilómetro de la Cañada Real, que en su origen era una tradicional vía pecuaria que situada hoy en día al lado de la autopista M50 (la tercera circunvalación exterior de Madrid) y que es considerada una zona especialmente problemática en cuanto a drogas y delincuencia. El municipio de Madrid desarrolló un Programa de Intervención Social para la Cañada Real a partir del 2011 partiendo de un Informe Diagnóstico que se hizo conjuntamente con ACCEM en 2010.7 El programa tenía como objetivo cartografiar las necesidades de los menores que allí residían y proporcionar un servicio gratuito de autobús a las escuelas (ya que el transporte público era escaso y se encontraba sólo en el "primer tramo" de la Cañada). Sin embargo, el Programa de Intervención no incluía al Gallinero, un poblado chabolista que en 2016 contaba con aproximadamente 420 gitanos rumanos (de los cuales más del 60\% menores) que vivían ahí desde los años noventa, sin electricidad, sin sanitarios, sin sistema de alcantarillado, y con un solo acceso al agua para toda la comunidad.

Una voluntaria que durante los últimos años ha ayudado a proporcionar transporte a las escuelas para los niños que viven en El Gallinero, comentó sobre el tema:

Leyendo el texto que me mandas, ${ }^{8}$ efectivamente nada del Gallinero, parece que hay gitanos de primera y de segunda... iy los rumanos, de quinta! (intercambio de correo electrónico, octubre 2016).

\footnotetext{
${ }^{7}$ La información está disponible en la página web de la Comunidad de Madrid.

${ }^{8}$ El plan mencionado es el Mapa de Estudios sobre la Vivienda y la Población Gitana, realizado por la Fundación Secretariado Gitano y Daleph en 2015 y publicado en 2016
} 
Vinculada a la cuestión de la ciudadanía está la de las expectativas culturales que conlleva la nacionalidad. España exige a los extranjeros que solicitan la ciudadanía española que renuncien a cualquier otra ciudadanía que puedan tener. Sin embargo, esta condición no se aplica a los ciudadanos de los países latinoamericanos, ni a Andorra, Filipinas, Guinea Ecuatorial, Portugal o los judíos sefardíes: es decir, aquellos países/pueblos identificados como excolonias y/o que tienen algún grado de afinidad cultural. Para estas categorías, además de no tener la obligación de renunciar a la otra ciudadanía, el requisito de residencia para nacionalizarse es de dos años, mientras que es de cinco años para los refugiados y diez años para todos los demás. En términos de derechos y ciudadanía, esto se traduce en el hecho de que cualquier migrante de América Latina o Filipinas es visto como "culturalmente más cercano" que los inmigrantes provenientes de Rumania o de Bulgaria, a pesar del hecho de que sean europeos. El hecho que diferencias "nacionales" tengan, en general, más relevancia de diferencias "culturales" (al menos por los responsables políticos) se traslada en el hecho que los gitanos españoles vengan calificados como "españoles" en primer lugar, y "gitanos" en segundo lugar. Comentando sobre parejas mixtas entre gitanos y no gitanos en España, un responsable de las políticas de inclusión explicó su punto de vista de la siguiente manera:

Ver a parejas mixtas en España es muy común, muy común... las parejas mixtas lo eran antes ya en algunas zonas de España donde había tradición más de integración como algunas zonas de Extremadura, o de Andalucía, especialmente de Andalucía occidental, pero hoy en día esto es muy, muy común en todas partes. Pues porque al final si los gitanos van a la escuela con los no gitanos, lo que son los sentimientos identitarios, se van... y por lo tanto se casan con la persona con la cual mejor se relacionan y afectivamente mejor se entienden. [...] ¿Que quiere decir eso? Y vamos de nuevo al enfoque étnico: que ante todo en la sociedad primero somos personas, luego somos ciudadanos, y luego tenemos unas identidades. Es decir que primero están los derechos humanos de las personas, luego están el acceso a los servicios y los recursos sociales, derechos sociales, etcétera, y luego tienes tus identidades. Pero si pones tus identidades por delante de los aspectos fundamentales que son los derechos humanos etcétera etc., pues no hay posibilidad de integración (entrevista, abril 2015, Madrid).

Otro elemento o "categoría" de igualdad podría ser la residencia en un territorio específico. En España existen importantes niveles de autonomía regional, y los ámbitos políticos en los que los gobiernos regionales tienen mayor influencia (como legisladores/reguladores y administradores/ proveedores) son la asistencia sanitaria y la asistencia social (Vampa 2016, p. 98). Los recursos, la calidad de los servicios y las prestaciones sociales

por el Ministerio de Sanidad, Servicios Sociales e Igualdad en el marco del seguimiento de la Estrategia Nacional de Integración de la Población Gitana. 
varían considerablemente de una región a otra, y esa disparidad puede observarse tanto en el plano de los ingresos como en el de la política. Las regiones en las que se ha invertido más capital político y económico en programas sociales (proporcionalmente al PIB regional) son Navarra y el País Vasco, seguidas de Cataluña, Madrid y (a cierta distancia) Andalucía. Esto no se limita a las políticas dirigidas a los gitanos, sino que abarca también planes y estrategias para otras minorías (especialmente los migrantes). Los gitanos se identifican a menudo en los planes de integración regional como "gitanos andaluces", "gitanos catalanes", etc.

\section{La introducción al Plan Andaluz empieza así:}

Hacer política social significa trabajar para los más desfavorecidos, por aquellos que, por razones de diversa índole, viven en condiciones de pobreza, marginación, y en situaciones o en riesgo de exclusión social. En el caso de la Comunidad Gitana Andaluza, 'nuestra' minoría étnica por excelencia, y la más marginada históricamente, la Junta de Andalucía ha apostado fuerte desde los comienzos de nuestra andadura autonómica, por equipararla al resto de los andaluces, por conseguir los principios mínimos de igualdad y equidad que tanto la Constitución como nuestro Estatuto de Autonomía garantizan para TODOS los ciudadanos (Junta de Andalucía Consejería de Asuntos Sociales 1997, p. 7, énfasis presente en el texto original).

El plan continúa definiendo los objetivos estratégicos y los puntos de referencia, manteniendo siempre los "otros andaluces" como término de comparación, mientras que apenas hay referencia a España o a la población española en su conjunto. La importancia de la identidad regional en España puede observarse también en el hecho que varios gitanos, y no gitanos, se identifican en función de la región en la que residen, y no del Estado. Un miembro del Consejo de los Gitanos del País Vasco, por ejemplo, a la hora de definir su identidad lo puso así: "Soy gitano, soy vasco, y nada en el medio" (entrevista, septiembre 2014, Bilbao). Sin embargo, la identidad regional y la identidad nacional no tienen por qué estar en contradicción la una con la otra y, en general, si una comunidad gitana está arraigada en un territorio o región específica, entonces esa comunidad también pertenece a la política del Estado. Por lo tanto, no cabe duda de que los gitanos andaluces, los vascos, los castellanos, etc., sean españoles a los ojos del Estado español.

El "principio de territorialidad", aunque menos claro que la ciudadanía, tiene consecuencias importantes, ya que determinadas políticas como el acceso a la vivienda social suelen estar vinculadas a los requisitos de residencia (que incluyen, entre otras cosas, estar inscrito en el padrón 
municipal de habitantes). ${ }^{9}$ Dado que normalmente es necesario demostrar de haber estado empadronados en un sitio durante varios años para poder acceder a prestaciones sociales, este principio contribuye a reforzar la idea de que los gitanos españoles pertenecen a la "comunidad imaginada" y son "nuestros" gitanos, mientras que se ignora a los gitanos no españoles que, aunque sean ciudadanos europeos, son considerados más problemáticos y necesitados.

Otro aspecto a tener en cuenta es el nivel de recursos económicos, que también pueden problematizar o simplificar el acceso a y el ejercicio de los derechos y a la ciudadanía. El término "ius pecuniae" se acuñó para describir casos de "nacionalidad por inversión", como programas en los que se puede comprar ciudadanía o residencia, permitiendo a un individuo un acceso rápido a la ciudadanía o residencia permanente a cambio de una inversión monetaria significativa en un país (Boatca 2016).

Los casos de facilidades o ventajas de movilidad global para las personas muy adineradas afectan a números relativamente bajos de migrantes (Shachar y Baubock 2014), pero el mismo principio se aplica también a la inversa. Negar permisos de residencia, o hacer el proceso más difícil para aquellos migrantes que son vistos como una carga económica para la comunidad, se ha convertido en una práctica estándar en muchos países de la OCDE. ${ }^{10}$

La idea de la ciudadanía como una responsabilidad compartida para el bienestar económico puede, por lo tanto, ser usada como base para reclamos de más igualdad económica y más redistribución de riqueza dentro de la comunidad nacional, mientras que simultáneamente puede ser usada como un argumento en contra de la inclusión hacia los no ciudadanos, para lo cual se usa un cierto criterio económico como criterio para ser incluidos. Irónicamente, al crear planes ad hoc para los gitanos y para los sectores más marginados de la sociedad, el NRIS deslegitimó hasta cierto punto una reivindicación redistributiva más estructural, y muy necesaria sobre todo en tiempos de prolongada crisis económica (en 2020 la tasa de desempleo en España sigue siendo superior al 20\%).

\footnotetext{
9 En el caso de viviendas populares en Madrid, se requiere la prueba de diez años consecutivos de residencia en el municipio.

10 En España, por ejemplo, una serie de "regresos voluntarios" de familias gitanas originarias de Rumania han tenido lugar desde 2014, cuando las autoridades locales de Barcelona empezaron a poner en custodia de los servicios sociales a los menores de familias romaníes migrantes cuyas condiciones de vida y vivienda se consideraban "no aptas para criar a los hijos" (Vrăbiescu 2015).
} 
Las estrategias dirigidas a los gitanos fueron eficaces para poner en evidencia la exclusión socioeconómica generalizada a la que se enfrentan, pero el énfasis puesto en los "déficits" individuales de la población destinataria, visto a través de la lente de la falta de competencias educación o motivación, también refuerza la narrativa de los gitanos como víctimas y culpables de su marginación. Al yuxtaponer una corriente dominante "funcional" y "normal" (aunque los datos muestran que la desigualdad siga aumentando y afecta a gran parte de la población), crea una falsa dicotomía marginalidadnormalidad, des-problematizando las desigualdades estructurales y presentando la falta de "integración" como un fracaso personal. En este contexto, la formulación de medidas de austeridad y recortes en gastos sociales como una cuestión de "responsabilidad" y de cumplimiento de los requisitos de la UE, mientras que se adoptan medidas y programas económicos específicos para la población gitana, ha contribuido en cierta medida a la descripción étnica de la población gitana como "atrasada" y carente de la capacidad o la voluntad de integrarse en la sociedad en general. Aunque los gitanos no sean el único grupo estigmatizado o que ha sido particularmente afectado por la crisis económica, las medidas puestas en marcha como resultado de la Estrategia para la Inclusión de la Población Gitana reflejan la división en categorías "merecedoras" y "no merecedoras" presentes en el resto de políticas de ayudas sociales, y que acaban discriminando a los gitanos no españoles.

\section{Conclusiones}

Si bien la marginación y la discriminación que sufre la población gitana en Europa no son algo nuevo, la importancia política de esta cuestión ha aumentado en el último decenio, tanto a nivel europeo como nacional. Esto, a su vez, ha hecho necesario que los responsables políticos y los administradores definan quiénes constituye la población gitana y enmarquen su presencia y estatus en términos jurídicos y políticos.

Este capítulo ha abordado el hecho de que existe un amplio consenso en cuanto a que las personas gitanas en España sufren de discriminación estructural, pero hasta ahora se han realizado limitados esfuerzos para adoptar un enfoque que permita comprender cómo se manifiesta dicha discriminación compleja en las políticas públicas.

España ha sido presentada a menudo como un modelo positivo en cuanto a la integración de los gitanos, pero lo que se desprende de un análisis más detallado de sus políticas es que las expectativas de integración de los gitanos parecen reflejar y estar conectadas al sentido de pertenencia del país, más que a otra cosa. O sea, si por un lado ha habido un esfuerzo por parte 
del estado para desarrollar un enfoque "explicito, pero no exclusivo" que podría ser interpretado de forma interseccional, este marco también presenta muchos ciegos que terminan invisibilizando gitanos que no caben en la "combinación" de desigualdad que conceptualiza a los destinatarios de las políticas como gitanos españoles que se enfrentan a una desigualdad de tipo socioeconómico.

La fórmula "enfoque explícito, pero no exclusivo" suena bien, pero es difícil adaptarlo a la situación de los inmigrantes gitanos en España, que presentan un reto interseccional distinto de los previstos en el marco español: es muy probable que las medidas explícitas desarrolladas en los poblados chabolistas habitados por gitanos inmigrantes acaben siendo "exclusivas", mientras que las medidas no exclusivas sean tampoco explicitas, en cuanto se trata principalmente de servicios de welfare en distritos pobres. Se puede concluir que es más probable que este principio de enfoque específico, pero no exclusivo, funcione en áreas bien definidas, como en ciertos distritos concretos habitados prevalentemente por gitanos españoles.

Sin embargo, la dimensión política de la exclusión y la marginación casi nunca está realmente separada de las desigualdades culturales o económicas, o de ambas: para los no ciudadanos que gozan de un sentido de pertenencia cultural y reconocimiento en el país de acogida, y que no sufren de dificultades económicas y de la inseguridad personal que conlleva, el acceso a la ciudadanía es en gran medida superflua. Pero es cuando un grupo no tiene acceso a los derechos culturales o económicos que la falta de derechos cívicos y políticos tiene un alto costo. La cuestión más amplia que esto plantea es que, dado que desarrollar políticas de inclusión/integración que abarquen las complejas realidades y desigualdades múltiples existentes en varios contextos es, aunque con las mejores intenciones, inviable a partir desde un modelo abstracto, sería preferible, aunque más complicado, trabajar 'hacia arriba' a partir de realidades locales concretas.

\section{Bibliografía}

Anderson, Benedict (1991): Imagined Communities: Reflections on the Origin and Spread of Nationalism, Verso.

Bereményi, Balint-Ábel, y Anna Mirga (2012): Lost in Action? Evaluating the 6 years of the Comprehensive Plan for the Gitano Population in Catalonia, Barcelona: FAGiC and EMIGRA/CER-M.

András Bíró, Nicolae Gheorghe et al. coord. (2013): From Victimbood to Citizenship. The Path of Roma Integration, Budapest: Pakiv European Roma Fund.

Boatca, Manuela (2016): «Exclusion through Citizenship and the Geopolitics of Austerity» en S. Jonsson y J. Willén edtr., Austere Histories in European Societies. Social Exclusion and the Contest of Colonial Memories, Taylor y Francis, p. 1-20. 
Carrasco, Silvia y Gabriela Poblet (2019): «Overview of the integration of Roma citizens in Spain and some transferable lessons for the EU», NESET ad hoc question [en línea] No. 4/2019. Disponible en: bttps://nesetweb.eu/wpcontent/uploads/2019/10/NESET_AHQ4_2019.pdf [Acceso 2 noviembre 2019]

Charnon-Deutsch, Lou (2004): The Spanish Gypsy: The History of a European Obsession. The Pennsylvania State University Press.

Dzankic, Jelena (2012): «The Pros and Cons of Ius Pecuniae: Investor citizenship in comparative perspective», EUI Working Papers, 14 [en línea]. Disponible en: https:/ / cadmus.eui.eu/ handle/1814/21476 [Acceso 2 noviembre 2019].

European Commission (2011), Communication from the Commission to the European Parliament, the Council, the European Economic and Social Committee and the Committee of the Regions. An EU Framework for National Roma Integration Strategies up to 2020. COM(2011) 173/4 [en línea]. Brussels: European Commission. Disponible en: https://eurlex.europa.eu/legal-content/ en/ALL/ ?uri=CELEX\%3 A52011DC0173

[Acceso 2 noviembre 2019].

European Roma and Travellers Forum (2016): Fact Sheet on the Situation of Roma in Spain [en línea]. Disponible en: http://mww.presenciagitana.org/ The_situation_of_Roma_in_Spain_06012016.pdf [Acceso 2 noviembre 2019].

Fraser, Nancy (2008): Scales of Justice. Reimagining Political Space in a Globalizing World. Cambridge: Polity Press.

Gómez Alfaro, Antonio (1993): La Gran Redada de Gitanos. Madrid: Presencia Gitana.

Hauben, Paul (1979): «The Enlightenment and Minorities: Two Spanish Discussions», The Catholic Historical Review 65 (1), p. 1-19.

Junta de Andalucía Consejeria de Asuntos Sociales (1997): Plan Integral para la Comunidad Gitana de Andalucía.

Kostka, Joanna (2015): «Implementation of Roma Inclusion Policies: Why Defining the Problem Matters», Social Inclusion 3(5), p. 78-89.

Magazzini, Tina y Stefano Piemontese (2016): «'Roma’ Migration in the EU: The Case of Spain between 'new' and 'old' Minorities», Migration Letters 13 (2), p. 228-41.

Magazzini, Tina (2018): «What's in a name? Causes and consequences of labeling minorities as 'national' or 'migrant': Roma in Italy and Spain», International Migration, Vol.56, p. 203-220.

Martín, David (2017): El Pueblo Gitano en Euskal Herria. Orkoien: Txalaparta.

Gobierno de España, Ministerio de Sanidad Servicios Sociales e Igualdad (2012): «Estrategia Nacional para la Inclusión Social de la Población Gitana en España 2012-2020» [en línea]. Disponible en: bttps:// www.mscbs.gob.es/ssi/familiasInfancia/PoblacionGitana/docs/WEB_POB LACION_GITANA_2012.pdf [Acceso 2 noviembre 2019].

O'Nions, Helen (2011): «Roma Expulsions and Discrimination: The Elephant in Brussels», European Journal of Migration and Law 13(4), p. 361-88.

Said, Edward Wadie (1978): Orientalism, London and Henley: Routledge and Kegan Paul Ltd. 
Shachar, Ailet, y Rainer Bauböck (2014): «Should Citizenship Be for Sale? », SSRN Electronic Journal [en línea]. Disponible en: https://cadmus.eni.eu/ bitstream/handle/1814/29318/RSCAS_2014_01.pdf [Acceso 2 noviembre 2019].

Stewart, Michael, edtr. (2012): The Gypsy "Menace". Populism and the New Anti-Gypsy Politics, London: Hurst y Company.

Vrăbiescu, Ioana (2019): «Dwelling in Limbo. Temporality in the Governance of Romani Migrants in Spain» en T. Magazzini y S. Piemontese edtr., Constructing Roma Migrants, IMISCOE Research Series, Springer, Cham, p. 109-128.

Vampa, Davide (2016): «The Regional Politics of Welfare in Italy, Spain and Great Britain», Leicester, UK: Palgrave Macmillan, Springer International Publishing.

Vega Cortés, Agustín (1997): «Los Gitanos En España» Barcelona: Jovenes contra la intolerancia» Unión Romaní. Disponible en: http://www.unionromani.org/ bisto.htm [Acceso 2 noviembre 2019]

Vermeersch, Peter (2012): «Reframing the Roma: EU Initiatives and the Politics of Reinterpretation», Journal of Ethnic and Migration Studies 38(8), p. 1195-1212.

Yildız, Can y Nicholas De Genova (2017): «Un/Free mobility : Roma migrants in the European Union», Social Identities 23(4), p. 1-1 